Research Paper:

\title{
The Relationship Between Family Function, Perfectionism and Hidden Anxiety of Students
}

\author{
Shahnam Abolghasemi ${ }^{1^{*}} \mathbf{Q}$, Jamile Tavakoli Azad ${ }^{2}$, Maryam Biabani Asli ${ }^{2} \mathrm{Q}$, Nasrin Naderifar $^{2}$ \\ 1. Department of Psychology, Tonekabon Branch, Islamic Azad University, Tonekabon, Iran. \\ 2.Department of Psychology, Rasht Branch, Islamic Azad University, Rasht, Iran.
}

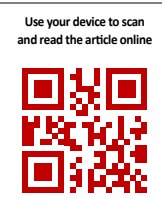

Citation Abolghasemi Sh, Tavakoli Azad J, Biabani Asli M, Naderifar N. The Relationship Between Family Function, Perfectionism and Hidden Anxiety of Students. Avicenna J of Neuropsychophysiology. 2018; 5(3):107-112. http://dx.doi.org/10.32598/ ajnpp.5.3.107

http://dx.doi.org/10.32598/ajnpp.5.3.107

Keywords:

Family performance, Positive perfectionism, Negative perfectionism, Hidden anxiety

\begin{abstract}
Introduction: Perfectionism and anxiety are formed by the family and parents among children.

Objectives: The purpose of this study was to investigate the relationship between family function, perfectionism, and hidden anxiety.

Materials and Methods: This descriptive-correlational study was done on 220 students of Rasht city. Family Assessment Device (FAD), Positive and Negative Perfectionism Questionnaire, and Spielberger state-trait anxiety inventory were used to collect data. Data were analyzed by SPSS 22.0 using correlation and and multiple regression analysis.
\end{abstract}

Results: The results of multiple regression analysis showed a correlation between family function perfectionism, and hidden anxiety $(\mathrm{P}<0.01)$.

Conclusion: It can be concluded that there was a significant relationship between family function, perfectionism, and hidden anxiety.

\section{Introduction}

$\mathrm{n}$ a healthy family, different patterns of communication are served over time. These patterns form the family, and through determining the role of family members, they determine the domain of each member's behavior and facilitate their exchange of ideas [1], by which the essential bases of an individual's personality development can form [2]. The family's function is associated with its ability to adapt to changes, resolve contradictions, solidify members, succeed in applying disciplinary disciplines, observe the boundaries between individuals and implement the rules and principles governing it to protect the entire family system [3].

Based on the studies done on behavioral disorders, it can be concluded that behavioral disorders are more due to the relationship between parents and the child followed by the inherited and biological factors. Moreover, researchers have reported a relationship between parental abuse and behavioral disorder in the child.

* Corresponding Author:

Shahnam Abolghasemi, PhD.

Address: Department of Psychology, Rasht Branch, Islamic Azad University, Rasht, Iran.

Tel: +98 (911) 3913907

E-mail: sh.abolghasemi@toniau.ac.ir 
This relationship is significant and indicates that the family and, especially the behavior of parents during childhood play an essential role in the development of behavioral disorders during childhood and adolescence [4]. several studies have been done on the relationship between family function and anxiety [5], obsessive beliefs [5], perfectionism and negligence [6], deviant behavior [7], excitement and aggression [8], prevention of risk of high-risk behaviors [9], childhood physical symptoms, anxiety, sleep disturbance, depression and social function disorder [10], and addiction in children [11].

Perfectionism is a personality trait, which is affected by the family and parents to develop in the children. It refers the tendency of a person to have a set of extreme measures, focusing on failures and violations in performance, belief in being complete, a feeling of anxiety and high psychological pressure as well as being scared that he will not be able to fulfill his expectations [12]. According to Lee et al. [13] study, positive and negative perfectionism are different. Positive perfectionism is defined as trying to arrive at reasonable and realistic criteria, whereas negative perfectionism is the tendency to attempt to achieve very high standards, which is associated with the fear of failure focusing on disgusting others [14].

The family function can be associated with the emotional problems, such as anxiety. Anxiety is a multidimensional factor, which consists of two main dimensions, including hidden and apparent anxiety. Hidden anxiety indicates the person's personality anxiety and some people are more likely to develop this type of anxiety than others. Hidden anxiety occurs through struggling with stress. On the other hand, the apparent anxiety occurs in a particular situation, where a person has the tense and contradicting feeling against it and also he does not have self-control [15]. In families, where the family system is far from the ordinary and desirable performance, the risk of psychological disorders, such as anxiety increases.

Due to the important role of students in the progress of each country, their psychological health is essential, and the factors affecting their psychological health must be identified and be used in relevant controlling programs. In this regard, the present research aimed to find a relationship between family functioning, and perfectionism and hidden anxiety among students.

\section{Materials and Methods}

The present descriptive-correlation study was done on all university students of Rasht city $(44,628$ students) from 16 scientific and academic centers. Using the convenient sampling method, 220 students were selected. Referring to the colleges and libraries of Rasht universities, students who were willing to participate in the research were asked to respond to research questionnaires. The participants filled out the informed consent form, as well.

\section{Family Assessment Device (FAD)}

FAD is a 60-item instrument that is made based on the McMaster model of family functioning. It assesses seven areas, including problem-solving, role relationship, emotional response, emotional involvement, behavioral control, and overall performance. The higher score of this scale indicates ineffective functioning. Cronbach's alpha coefficient for its sub-scales was reported from 0.88 to 0.91 . The correlation coefficients were calculated for four-week intervals from $r=0.83$ to $r=0.89$ in two turns [16]. The validity of FAD has been reported in some studies in Iran up to 0.91 and 0.93 , and also the alpha coefficients for its subscales have been reported from 0.72 to 0.92 [17]. In the current study, its reliability obtained $\alpha=0.89$.

\section{Positive and Negative Perfectionism Questionnaire (PANPS)}

PANPS was designed by Terry-Short et al. [18] with 40 items, of which 20 items measure positive perfectionism and 20 others evaluate negative perfectionism. Each item is scored on a five-point Likert scale measuring the perfectionism of the subjects from one to five in both the positive and negative fields. The minimum score is 20 and the maximum score is 100 . Terry-Short et al. [18] presented the Cronbach's alpha of 0.83 and 0.81 for the positive and negative perfectionism, respectively. In the Persian version of PANPS, the Cronbach's alpha for the questions of each sub-scale in a sample of 212 students was 0.90 and 0.87 for all subjects and 0.91 and 0.88 for male students, indicating the higher internal consistency of this scale. Basharat [19] indicated a correlation between the test scores based on a four-week re-test for 212 subjects ( $r=0.86)$, which shows the appropriate validity of this scale.

\section{Spielberger State-Trait Anxiety Inventory (STAI)}

The First version of the STAI was introduced by Spielberg et al. in 1970. It consists of 40 questions, of which the first 20 questions assess the state anxiety, and the next 20 questions measure trait anxiety. The scores of both parts can range from 20 to 80 . The state-trait 
questionnaire with an accepted credibility, reliability, and validity can be used in different populations. A correlation between STAI and Cattle's Anxiety Inventory also shows its validity. Chadri [20] reported the correlations of 0.92 and 0.89 for the English and the Bengali forms in women and men, respectively for state anxiety, and 0.94 and 0.91 for the trait anxiety, respectively. The correlation 0.79 to 0.83 was found between STAI and Taylor Manifest Anxiety Scale. The correlation between Taylor Manifest Anxiety Scale and Anxiety Scale Questionnaire and the trait-STAI is close to the validity of these scales, they are seemingly usable to assess the trait anxiety. In the study by Bong [21], the Cronbach's alpha of 0.91 approved the validity of the state-STAI. The Cronbach's alpha method was used to calculate the validity of the trait-STAI (hidden anxiety), which was obtained 0.90 for a normal sample of 600 people. Data were analyzed by SPSS V. 22 using correlation and multiple regression analysis.

\section{Results}

A total of 100 participants were male and 120 subjects were female students. The Mean \pm SD age of female and male students was $27.8 \pm 6.9$ and $28.1 \pm 9.9$, respectively. Data analysis results are presented in Table 1.

The results of this study using the multivariate regression showed a significant correlation between family function, perfectionism, and hidden anxiety $(P<0.01)$.

\section{Discussion}

Based on the results, the relationship between family function and positive and negative perfectionism as the research hypothesis was confirmed. Accordingly, family function and positive and negative perfectionism are correlated. These results are consistent with the results of Mandel et al. [22] and Affrunti [23]. To explain this finding, it can be said that behavioral control is the

Table 1. Correlation between the components of family function, positive perfectionism, negative perfectionism, and hidden anxiety

\begin{tabular}{|c|c|c|c|c|}
\hline Family Function Components & Positive Perfectionism & Negative Perfectionism & Hidden Anxiety & Significance Level \\
\hline Problem solving & 0.25 & 0.24 & -0.19 & 0.001 \\
\hline Role relationship & 0.23 & -0.56 & -0.12 & 0.001 \\
\hline Emotional response & 0.54 & 0.29 & -0.54 & 0.001 \\
\hline Emotional involvement & 0.27 & -0.37 & 0.33 & 0.001 \\
\hline Behavior control & 0.28 & 0.22 & -0.20 & 0.001 \\
\hline Overall function & 0.31 & -0.34 & -0.21 & 0.001 \\
\hline
\end{tabular}

AJNPP

Table 2. Standard and non-standard coefficients of the family function and positive perfectionism

\begin{tabular}{|c|c|c|c|c|c|}
\hline \multirow{2}{*}{ Variable Coefficient Predictors } & \multicolumn{2}{|c|}{ Non-standard Coefficients } & \multicolumn{3}{|c|}{ Standard Coefficients } \\
\hline & B & Standard Estimated Error & Beta & $\mathbf{t}$ & Sig. \\
\hline Fixed value & 59.26 & 3.29 & - & 15.89 & 0.001 \\
\hline Emotional Response & 2.09 & 0.079 & 0.94 & 26.51 & 0.001 \\
\hline Emotional involvement roles & 1.77 & 0.073 & 1.35 & 24.11 & 0.001 \\
\hline Behavior control & 0.965 & 0.065 & 1.39 & 14.80 & 0.001 \\
\hline Overall performance & 0.419 & 0.086 & 0.42 & 4.88 & 0.001 \\
\hline Problem-solving & 1.16 & 0.182 & 0.548 & 6.37 & 0.001 \\
\hline relationship & 0.375 & 0.112 & 0.209 & 3.36 & 0.001 \\
\hline
\end{tabular}


Table 3. Standard and non-standard coefficients of family function components and negative perfectionism

\begin{tabular}{ccccccc}
\hline \multirow{2}{*}{ Variable Coefficient Predictors } & \multicolumn{2}{c}{ Non-standard Coefficients } & \multicolumn{3}{c}{ Standard Coefficients } \\
\cline { 2 - 7 } & B & Standard Estimated Error & Beta & t & Sig. \\
\hline Fixed value & 59.17 & 3.77 & - & 15.70 & 0.001 \\
\hline Relationship & -3.76 & 0.20 & -0.794 & -23.43 & 0.001 \\
\hline Emotional involvement overall performance & -6.51 & 0.21 & -1.49 & -30.34 & 0.001 \\
\hline Emotional response & 3.87 & 0.23 & 1.520 & 16.66 & 0.001 \\
\hline Problem solving & 7.78 & 0.45 & 1.10 & 16.99 & 0.001 \\
\hline Behavior control & 2.93 & 0.19 & 1.26 & 15.25 & 0.001 \\
\hline
\end{tabular}

AJNPP

Table 4. Standard and non-standard coefficients of the family function and hidden anxiety

\begin{tabular}{cccccc}
\hline & \multicolumn{2}{c}{ Non-standard Coefficients } & \multicolumn{2}{c}{ Standard Coefficients } \\
\cline { 2 - 5 } Variable Coefficient Predictors & B & Standard Estimated Error & Beta & $\mathbf{t}$ & Sig. \\
\hline Fixed value & -39.32 & 1.10 & - & -35.81 & 0.001 \\
\hline Emotional response & -3.32 & 0.035 & -1.21 & -94.78 & 0.001 \\
\hline Emotional involvement & 2.53 & 0.034 & 1.58 & 75.26 & 0.001 \\
Overall performance & -0.16 & 0.033 & -0.13 & -4.98 & 0.001 \\
\hline Behavior control & -0.87 & 0.029 & -1.02 & -30.19 & 0.001 \\
Problem solving & -1.58 & 0.057 & -0.60 & -27.50 & 0.001 \\
\hline Role & -0.17 & 0.016 & -0.18 & -10.57 & 0.001 \\
\hline
\end{tabular}

AJNPP

most predictor for positive perfectionism. A favorable psychological climate of the family coupled with the sense of mutual responsibility, provide an appropriate environment for gaining positive qualities, such as targeting, trying for excellence and order and organization. Also, most of the perfectionists are raised in families, in which less-than-perfect performance of the members is responded by overt or implicit critique. As a result, the children of these expectant families may learn critical methods for evaluating their performances.

Moreover, in explaining the relationship between family function and negative perfectionism, it can be said that the low performance of family shows a low level of control in children over their destiny, and also they have to coordinate with the goals and roles determined by parents for them. However, the parents' emphasis is on the wishes and expectations of their children. In families with lower function, parents express their wishes more clearly, and their children will find that they will be provided by parental support by fulfilling these demands.

The results also showed a relationship between family function and hidden anxiety. Accordingly, family function, and hidden anxiety are correlated. These results are consistent with the results of Klibert et al. [24] and confirm their findings. The emotional response was the strongest predictor for hidden anxiety. In explaining this finding, it can be said that what goes on inside the family is a crucial factor in creating flexibility and reducing the present and future risks associated with adverse events and inappropriate conditions. Therefore, disturbance in the function of the family causes its members to be confused, worried and faced with challenges to communicate and the health of its members endangers. Also, a high level of emotional conflict and a low capacity for adjustment to stress are observed in these families [25]. 
It seems that the positive atmosphere of coherent families combined with the sense of mutual responsibility is a good basis for gaining positive qualities, such as targeting, trying for excellence and order and organization. Regarding the variability of family flexibility, the findings of this study indicated that flexibility predicts both the positive and negative aspects of perfectionism [26]. In other words, the flexibility of the family, with an increase in the positive and negative dimensions of perfectionism, has a dual function. Studies have shown that flexibility, in contrast to family cohesion (which always leads to positive outcomes), has no fixed findings, especially in traditional and collectivist cultures.

From the Minuchin structural and therapeutic perspective, one of the leading causes of anxiety in a child, in addition to the conflicts between parents and other members of the family, can be the transmission of problems within the family system to one another, especially children and forming the triangles in the family members' relationships, especially parents with children [27]. Anxiety disorder is considered as a part of chronic border problems in diagnosing all kinds of structural disabilities in disturbed families, which caused by transferring stresses from one subunit to others [28]. Using a particular person by a subunit who is not a member of its subordinate to expand a sub-objective conflict can degrade the situation.

This situation is often observed when parents use a child to distract or discourage marital conflicts. In this case, the boundary between the parents and the child becomes unclear, by which the parents increase the development of childhood disorders. The parents then try to unite to care for him. In such a situation, the goal of the therapist is to reconstruct the organization of the subunit, according to the pattern of parenting and the child [29].

\section{Ethical Considerations}

\section{Compliance with ethical guidelines}

All ethical principles were considered in this article. The participants were informed about the purpose of the research and its implementation stages; they were also assured about the confidentiality of their information.

\section{Funding}

This research did not receive any specific grant from funding agencies in the public, commercial, or not-forprofit sectors.

\section{Authors' contributions}

All authors contributed equally in preparing all parts of the research.

\section{Conflict of interest}

The authors declared no conflict of interest.

\section{References}

[1] Uji M, Sakamoto A, Adachi K, Kitamura T. The impact of authoritative, authoritarian, and permissive parenting styles on children's later mental health in Japan: Focusing on parent and child gender. Journal of Child and Family Studies. 2014; 23(2):293-302. [DOI:10.1007/s10826-013-9740-3]

[2] Barton AL, Kirtley MS. Gender differences in the relationships among parenting styles and college student mental health. Journal of American College Health. 2012; 60(1):21-6. [DOI:10.1080/07448 481.2011.555933] [PMID]

[3] Wang KT. Personal and family perfectionism of Taiwanese college students: Relationships with depression, self-esteem, achievement motivation, and academic grades. International Journal of Psychology. 2012; 47(4):305-14. [DOI:10.1080/00207594.2011.626050] [PMID]

[4] Cascio VL, Guzzo G, Pace F, Pace U. Anxiety and self-esteem as mediators of the relation between family communication and indecisiveness in adolescence. International Journal for Educational and Vocational Guidance. 2013; 13(2):135-49. [DOI:10.1007/s10775013-9243-1

[5] Zhou X, Zhu H, Zhang B, Cai T. Perceived social support as moderator of perfectionism, depression, and anxiety in college students. Social Behavior and Personality: An International Journal. 2013; 41(7):1141-52. [DOI:10.2224/sbp.2013.41.7.1141]

[6] Lyke J, Matsen J. Family functioning and risk factors for disordered eating. Eating Behaviors. 2013; 14(4):497-9. [DOI:10.1016/j.eatbeh.2013.08.009] [PMID]

[7] Park MH, Chang KD, Hallmayer J, Howe ME, Kim E, Hong SC, et al. Preliminary study of anxiety symptoms, family dysfunction, and the Brain-Derived Neurotrophic Factor (BDNF) Val66Met genotype in offspring of parents with bipolar disorder. Journal of Psychiatric Research. 2015; 61:81-8. [DOI:10.1016/j.jpsychires.2014.11.013] [PMID]

[8] Affrunti NW, Woodruff-Borden J. Perfectionism in pediatric anxiety and depressive disorders. Clinical Child and Family Psychology Review. 2014; 17(3):299-317. [DOI:10.1007/s10567-014-0164-4] [PMID]

[9] Affrunti NW, Gramszlo C, Woodruff-Borden J. Executive function moderates the association between fearful temperament and dimensions of perfectionism. Personality and Individual Differences. 2016; 89:117-22. [DOI:10.1016/j.paid.2015.10.012]

[10] Martinez W, Polo AJ, Carter JS. Family orientation, language, and anxiety among low-income Latino youth. Journal of Anxiety Disorders. 2012; 26(4):517-25. [DOI:10.1016/j.janxdis.2012.02.005] [PMID] 
[11] Affrunti NW, Woodruff-Borden J. Negative affect and child internalizing symptoms: The mediating role of perfectionism. Child Psychiatry \& Human Development. 2016; 47(3):358-68. [DOI:10.1007/ s10578-015-0571-x] [PMID]

[12] Affrunti NW, Woodruff-Borden J. The associations of executive function and temperament in a model of risk for childhood anxiety. Journal of Child and Family Studies. 2015; 24(3):715-24. [DOI:10.1007/s10826-013-9881-4]

[13] Vaillancourt T, Haltigan JD. Joint trajectories of depression and perfectionism across adolescence and childhood risk factors. Development and Psychopathology. 2018; 30(2):461-77. [DOI:10.1017/ S0954579417000979] [PMID]

[14] Timpano KR, Carbonella JY, Keough ME, Abramowitz J, Schmidt NB. Anxiety sensitivity: An examination of the relationship with authoritarian, authoritative, and permissive parental styles. Journal of Cognitive Psychotherapy. 2015; 29(2):95-105. [DOI:10.1891/08898391.29.2.95

[15] Sánchez-Queija I, Oliva A, Parra Á, Camacho C. Longitudinal analysis of the role of family functioning in substance use. Journal of Child and Family Studies. 2016; 25(1):232-40. [DOI:10.1007/ s10826-015-0212-9]

[16] Boone L. Are attachment styles differentially related to inter personal perfectionism and binge eating symptoms? Personality and Individual Differences. 2013; 54(8):931-5. [DOI:10.1016/j. paid.2013.01.006]

[17] Ghanizadeh A, Shams F. Children's perceived parent-child relationships and family functioning in attention-deficit/hyperactivity disorder. Child \& Family Behavior Therapy. 2007; 29(3):1-11. [DOI:10.1300/J019v29n03_01]

[18] Kins E, Soenens B, Beyers W. Separation anxiety in families with emerging adults. Journal of Family Psychology. 2013; 27(3):495505. [DOI:10.1037/a0032869] [PMID]

[19] Baskin-Sommers A, Krusemark E, Ronningstam E. Empathy in narcissistic personality disorder: From clinical and empirical perspectives. Personality Disorders. 2014; 5(3):323-33. [DOI:10.1037/ per0000061] [PMID] [PMCID]

[20] Smith MM, Vidovic V, Sherry SB, Stewart SH, Saklofske DH. Are perfectionism dimensions risk factors for anxiety symptoms? A meta-analysis of 11 longitudinal studies. Anxiety, Stress, \& Coping. 2018; 31(1):4-20. [DOI:10.1080/10615806.2017.1384466] [PMID]

[21] Bong M, Hwang A, Noh A, Kim SI. Perfectionism and motivation of adolescents in academic contexts. Journal of Educational Psychology. 2014; 106(3):711-29. [DOI:10.1037/a0035836]

[22] Mandel T, Dunkley DM, Moroz M. Self-critical perfectionism and depressive and anxious symptoms over 4 years: The mediating role of daily stress reactivity. Journal of Counseling Psychology. 2015 62(4):703-17. [DOI:10.1037/cou0000101] [PMID]

[23] Affrunti NW, Woodruff-Borden J. The roles of anxious rearing, negative affect, and effortful control in a model of risk for child perfectionism. Journal of Child and Family Studies. 2017; 26(9):254755. [DOI:10.1007/s10826-017-0767-8]

[24] Klibert J, Lamis DA, Naufel K, Yancey CT, Lohr S. Associations between perfectionism and generalized anxiety: Examining cognitive schemas and gender. Journal of Rational-Emotive \& CognitiveBehavior Therapy. 2015; 33(2):160-78. [DOI:10.1007/s10942-0150208-9]
[25] Gaviţa OA, Joyce MR, David D. Cognitive behavioral parent programs for the treatment of child disruptive behavior. Journal of Cognitive Psychotherapy. 2011; 25(4):240-56. [DOI:10.1891/08898391.25.4.240]

[26] Gentes EL, Ruscio AM. Perceptions of functioning in worry and generalized anxiety disorder. Cognitive therapy and research. 2014; 38(5):518-29. [DOI:10.1007/s10608-014-9618-8]

[27] Sullivan PJ, Keller M, Paternostro J, Friedberg RD. Treating emotionally dysregulated and perfectionistic youth with transdiagnostic cognitive behavioral procedures. Journal of Contemporary Psychotherapy. 2015; 45(3):151-8. [DOI:10.1007/s10879-014-9293-9]

[28] Dunkley DM, Berg JL, Zuroff DC. The role of perfectionism in daily self-esteem, attachment, and negative affect. Journal of Personality. 2012; 80(3):633-63. [DOI:10.1111/j.1467-6494.2011.00741.x] [PMID]

[29] Cloninger CR, Zohar AH, Hirschmann S, Dahan D. The psychological costs and benefits of being highly persistent: Personality profiles distinguish mood disorders from anxiety disorders. Journal of Affective Disorders. 2012; 136(3):758-66. [DOI:10.1016/j. jad.2011.09.046] [PMID] 